\title{
REGULATION OF BEHAVIOR AND ATTENTION IN ESTONIAN, FINNISH, AND SWEDISH PEER INTERACTION 1
}

\author{
Boel De Geer, Tiia Tulviste and Luule Mizera
}

\begin{abstract}
The aim of this study is to compare the regulatory speech used by Estonian, Finnish, and Swedish kindergarten children. 62 dyads with children of 3-6 years were videotaped during play. All regulatory speech was coded according to play situation (game play or free play), focus of regulation (behavior or attention), addressee (peer or both), sentence form, pragmatic form, and outcome (response). The results confirm earlier studies and show a more symmetrical interaction in the Swedish group (S) than in the Estonian (E) and Finnish (F) groups. E and F were found to be more controlling than S, both in behavior and in attention regulation. Further, $\mathrm{E}$ and $\mathrm{F}$ were more direct in regulation, using imperatives as orders and preventing utterances, rather than declaratives or questions, which were most frequent in the $\mathrm{S}$ data. Although the outcomes of peer regulation were mainly compliance in all groups, $\mathrm{S}$ more often negotiated regulation. E and $\mathrm{F}$ were more often silent following regulation.
\end{abstract}

Keywords: Pragmatic socialization, Peer discourse, Regulation, Behavioral directives, Cross-cultural comparison.

\section{Introduction}

In the course of pragmatic socialization parents have been found to focus on children's language and its use in different situations (Becker 1988, 1990; Blum-Kulka 1997). The term language socialization is used by Ochs (1996) to describe both the processes of language acquisition and socialization, children acquire language and social and cultural competence in an integrated process, starting already during infancy. Several studies have shown that both the extent to which adults use language as an instrument of socialization, and the ways in which they use it, can vary between different cultures (e.g. Heath 1983; Schieffelin \& Ochs 1986; Ochs 1988; Kulick 1990), as well as within cultures, depending on context and participants (Andersen 1990). In the process of language socialization adults' input language guides the children towards an understanding of the socially appropriate verbal and non-verbal behavior of their culture

1 Research for this article was supported by grants from the Baltic Foundation in Sweden (No 31103). We thank Dr. Marja-Terttu Tryggvason for collection, transcription and analysis of the Finnish data. 
(Andersen 1990). Rauno, ole nüüd inimene! 'Rauno, behave like a human being now!' uttered by an Estonian father towards his two-year-old son serves as one example of what language socialization can be about - trying to give children a cultural competence. Language socialization is, however, not only an adult-to-child directed activity but is best described as a bi- or multi-directional activity (Pontecorvo 1998; Schaffer 1999). Children are known to take an active part in regulating parents' behavior (De Geer \& Tulviste 2002) and in commenting on parents' as well as other adults' language and behavior (De Geer, Tulviste, Mizera \& Tryggvason 2002). Hence, language socialization is not only a matter of parental mediation of linguistic and cultural competence, but it is also a forum where linguistic and cultural competence is tried out and negotiated, together with adults and with peers.

Linguistic and cultural competence is thus not only achieved and practiced at home and with parents or other adults. Peer interaction also provides an arena for language socialization. The present study concerns cultural differences and similarities in regulation of behavior and attention among kindergarten peers of the ages 3-6 in Estonia, Finland and Sweden. We focus on two different play situations - game play and free play - and the frequency and use of regulative utterances. According to Goodwin (1990: 65) directives are utterances "designed to get someone else to do something". Furthermore, "directives are positioned right at the interface between language and social action; although built through speech, they are designed to make things happen in the larger world of social action within which talk is embedded" (Goodwin 1990: 65). We will hereafter equal the notions of behavior utterance and directive.

\subsection{Background}

Previous studies of parental regulation have shown cultural, social and individual differences (e.g. Bornstein, Tal, \& Tamis-LeMonda 1991; Clancy 1986; Halle \& Schatz 1994; Heath 1983; Hoff-Ginsberg 1991; Pan et al. 1996; Valsiner 1987). Among the differences were frequency in regulation and type of behavior expected from children. The differences were individual - child's age, sex, socio-economic or ethnical background, etc., contextual - home or institutional setting, number of persons present, etc., or task related - mealtime, book reading, problem solving, etc.

Previous comparisons of Estonian and Swedish maternal regulation have shown Estonian mothers to be more directive than Swedish mothers. In a study on maternal regulation of 2-year-old toddlers, Estonian mothers were found to use more behavior directives than Swedish mothers, and to regulate attention and physical activity more than verbal contributions (Junefelt \& Tulviste 1997). Another study of Estonian mothers of 2- and 4-year-old children has showed that Estonian mothers regulate physical behavior rather than speech also when the children are 4 years old (Tulviste and Raudsepp 1997). In both these studies mothers' regulation varies along context, both with regard to what is regulated and also to the frequency of regulation, e.g. in puzzle solving tasks the number of utterances regulating physical activity is higher than during mealtime situations.

In a study of family dinner interaction with children in the pre-adolescent ages (9-13 years) we found significant cultural differences in parents' regulation of child behavior (De Geer \& Tulviste 2002). Estonian mothers used significantly more 
behavior regulation than Swedish mothers. On the other hand, Swedish children regulated their parents' behavior more than Estonian children. Furthermore, Tulviste (2000) has studied socialization during meals in Estonian and American motheradolescent dyads (children's ages varying between 13 and 17) and found that Estonian mothers controlled the behavior of the children more frequently than the American mothers. Several authors distinguish between maternal directiveness vs. conversationeliciting styles - mothers who tend to be more concerned with eliciting children's conversational participation, and those talking to their children mainly with the aim to control their behavior (Halle \& Shatz 1994; McDonald \& Pien 1982). All our previous studies have found Estonian mothers to belong to the latter group.

\section{The present study}

This study focuses on three groups: Estonian, Finnish and Swedish kindergarten children, and its aim is to investigate the distribution across the three groups of the following: 1) the amount of regulation, 2) the play situation, 3) the focus of regulation, 4) the addressee of regulation, 5) the syntactic form of regulation, 6) the pragmatic form of regulation, and 7) the outcome following the behavior regulation.

\section{The amount of regulation}

Our first concern is regulation in relation to the total amount of speech, measured in utterances. This is an important measure, since a high rate of regulation per se will be more or less dominant, depending on the total amount of speech in a sample. According to the studies of e.g. Lehtonen (1993) and Sarjavaara \& Lehtonen (1997) adult Finns are more taciturn than Swedes. No comparative studies of adult Estonians as opposed to Finns and Swedes exist to our knowledge, but previous studies have shown that in family dinner interaction, Swedes talk more than both Finns and Estonians (Tulviste et al. 2003b). Tannen (1981: 236) claims that "Conversational style [...] is learned through communicative experience and is therefore influenced by family communicative habits". We would therefore expect Estonian and Finnish children to be less talkative than Swedish children, based on the fact that the children in all three groups will have acquired a norm of what amount of speech is appropriate in their homes.

The results of De Geer \& Tulviste (2002) showed that Estonian parents used a significantly larger amount of regulation than Swedish parents. Furthermore, Swedish children regulated their parents significantly more than Estonian children. According to Tulviste et al. (2004) Finnish mothers regulate their children like Swedish mothers, i.e. less than Estonian mothers. Further, Finnish children behave like Estonian children, in that they use regulation toward their parents in a low extent. In light of these results we could expect Estonian and Finnish children to use regulation on a very modest level and Swedish children to regulate each other more. On the other hand the opposite could be the case, at least for the Estonian children who, because of the high amount of regulation they have met at home, would regulate behavior to an extent similar to their parents, i.e. even more than the Swedish children. 
The play situation

The situation of playing a game vs. free play might result in different regulation behavior. The game play situation is competitive and could therefore give the children reason to regulate and restrict each other's behavior in a rather direct way. At the same time it is a cooperative activity, which could also create a need to regulate by suggestions and requests.

\section{The focus of regulation}

McDonald \& Pien (1982) distinguish between three types of regulation in mother-child interaction: Behavior regulation, attention regulation and speech regulation. The two regulation areas of this study are behavior and attention, whereas speech regulation will be treated in a separate study. In our previous study on family interaction (De Geer \& Tulviste 2002) we focused on behavior regulation only, after having discovered that attention regulation was extremely unusual in that context. However, we expect attention regulation to be more frequent in peer interaction.

\section{The addressee of regulation}

It would seem obvious that in a dyad there is only one possible addressee of an utterance - "the other". However, it is quite likely, and particularly in behavior regulation, where you aim "to get someone else to do something" (Goodwin 1990: 65), you could, as a means of mitigation, address "both”, i.e. "Let's do it!" or "Now we will play home." Following our earlier findings we would expect Swedish children to use more we-constructions when addressing their peers. Previous studies have shown that Swedish children (and adults) use more symmetric ways of interacting, in using a more indirect language (De Geer et al. 2002), and discussing and negotiating to a much higher extent than Estonian and Finnish children (De Geer et al. 2002; De Geer \& Tulviste 2002, 2004). Furthermore, the two different play situations - game play and free play - may trigger different uses of addressee. Game play is on the one hand a forced joint activity, which could give rise to more joint addressing, on the other hand it is a competitive activity, which could render more peer addressing. In free play, both possibilities seem likely - the children may chose to play more or less jointly and this choice could affect the ways of addressing in regulation.

\section{The syntactic form in regulation}

The syntactic form chosen in regulation is a further point of interest. Whereas syntactic forms are not necessarily cross-linguistically comparable in that they cannot be "translated" between languages, i.e. an Estonian imperative may not be equal to a Swedish one. However, we believe it is important to see what syntactic forms that are used in regulation by the different groups. Previous comparative studies on Estonian and Swedish child regulation have found that Estonian mothers of 2-year-olds are more likely to use imperatives, whereas Swedish mothers use declaratives (Junefelt \& 
Tulviste 1998; Tulviste 2000). Furthermore, in a family dinner interaction study on behavior regulation Swedes - both adults and children - were found to use declaratives and questions, whereas Estonians used imperatives (De Geer \& Tulviste 2002). Imperatives were also favored by Estonians and Finns, as opposed to Swedes - who preferred declaratives, in a study of metapragmatic comments in family dinner interaction (De Geer et al. 2002). It therefore seems reasonable to expect the young children in the three countries to use the same syntactic forms in regulations as adults and older children did in the previous studies.

\section{The pragmatic form of behavior regulation}

In trying to direct a person's behavior syntactic form is of course only one factor out of a larger complex, which consists of functional categories, such as command, suggestion, request, etc. as well as non-verbal cues. The syntactic form is merely the language's way of formulating the regulation, whereas the pragmatic form reveals the utterance's illocutionary force, which is perhaps cross-linguistically more comparable. Since previous studies have shown than Estonians and Finns are more direct in regulation than Swedes (De Geer et al. 2002), it seems likely to expect more commands from Estonian and Finnish children. A command can often be an imperative, but not necessarily. The statement $\mathrm{Nu}$ lyder du mig! "Now you are going to obey me! is, for instance, definitely a command. Swedish children are expected to use more indirect ways of regulating their peers, e.g. statements, suggestions or requests.

\section{The outcome of regulation}

The last aim of the study is to investigate the outcome of regulation, i.e. what, if any, reaction follows. We have showed in De Geer \& Tulviste (2002) that Estonian children comply much less with parental regulation than do Swedish children, who made less resistance. If previous research results are confirmed, i.e. that Estonian children regulate more than Swedish children, just like their parents, it would be interesting to see if also the outcome result will be repeated: Will Estonian children be less complying than Swedish children? Also, since Swedish children have been found to negotiate both parents' metapragmatic comments (De Geer et al. 2002) and each other's comments and behavior (De Geer \& Tulviste 2004), we would expect more negotiation following regulation from the Swedish children. Kuczinsky et al. (1987) found in their study of young children's (1;3 to 3;8 years old) compliance or non-compliance to maternal directives, that there were positive correlations between a mothers' indirect control strategies and child negotiation. Since the Swedish parental style of regulation has been found to be quite indirect, compared to the Estonian and Finnish styles, this lends further support for our hypothesis of negotiating Swedish children.

In conclusion, based on the results of previous studies, the following are our hypotheses. We expect that:

1. The Estonian and the Finnish children will be less talkative than the Swedish children. 
2. The Estonian and the Finnish children will use more regulation than the Swedish children.

3. Attention regulation will be more frequent in this study than in De Geer et al. (2002).

4. The Swedish children will use more we-constructions than the Estonian and the Finnish children when addressing peers.

5. All children will use the same syntactic forms in regulation as adults and older children.

6. The Estonian and the Finnish children will use more orders, whereas the Swedish children are expected to use more indirect means of regulation.

7. The Estonian - and maybe also the Finnish - children will be less complying than the Swedish children, who will negotiate regulation more than the Estonian and Finnish children.

\subsection{Data collection}

62 dyads were included in the study: 21 Estonian (Tallinn and Tartu), 19 Finnish (Oulu) and 22 Swedish dyads (Älvsjö, a southern suburb of Stockholm). All cities are considered "large" in their countries and have both universities and major industries. Stockholm and Tallinn are capitals, whereas Tartu and Oulu are not. The Stockholm suburb is, however, quite small and "small-townish", and Tallinn is indeed a very small capital.

All children's families were monocultural and monolingual speakers of Estonian, Finnish or Swedish. All children came from middle to upper middle class homes, as defined by the parents' education and occupation. One very obvious reason for choosing this group was that it would enable us to continue the research tradition in these social and geographic areas started already in the 1990's. Letters asking parents for permission to video record their children in a play situation together with a freely chosen peer were distributed to kindergartens in the above areas. The kindergarten staff collected parents' permissions.

Table 1 presents descriptive data on dyads and recording time per sample. Oneway analyses of variance (ANOVAs) were used to ascertain whether the duration of play varied as a function of Culture (Estonian vs Swedish vs Finnish). A one-way ANOVA revealed a significant effect of Culture (Estonian vs Swedish vs Finnish) on the average recording time of both the fishing game, $\mathrm{F}(2,121)=4.07, \mathrm{p}<.02$, and the free play, $F(2,121)=5.09, p<.01$. The results of the LSD tests showed that the average recording time of fishing game was significantly longer in the Swedish sample than in the Estonian and Finnish sample, whereas the average recording time of free play was significantly longer in the Finnish sample in comparison to other samples. The children's age ranged from 3.58 to 6.30 , the mean age did not differ significantly across samples. 
Table 1. Descriptive statistics on dyads and recording time

\begin{tabular}{llllll}
\hline & Estonian & Finnish & Swedish & ALL & \\
\hline Number of dyads & & & & & \\
$\quad$ - Girls' dyads & 10 & 19 & 22 & 62 & \\
$\quad$ - Boys'dyads & 10 & 9 & 6 & 31 & \\
$\quad$ - Mixed dyads & 1 & 0 & 5 & 6 & \\
Mean age (SD) & $5.36(0.58)$ & $5.10(0.45)$ & $5.13(0.54)$ & 5.20 & (0.54) \\
& & & & & \\
Mean recording time in minutes & & & & & \\
$\quad$ - Fishing game & $10.67^{\mathrm{S}}$ & $10.98^{\mathrm{S}}$ & $12.86^{\mathrm{E}, \mathrm{F}}$ & & \\
$\quad$ - Free play & $19.53^{\mathrm{F}}$ & $23.34^{\mathrm{E}, \mathrm{S}}$ & $19.68^{\mathrm{F}}$ & &
\end{tabular}

Note. Superscripts show significant differences across samples at $\mathrm{p}<.05$. The samples are marked as follows: $\mathrm{E}=$ Estonian, $\mathrm{F}=$ Finnish, $\mathrm{S}=$ Swedish

The recordings were performed by one researcher only, in order to influence the children as little as possible. The children were encouraged to choose a friend with whom they wanted to play. The Estonian and Finnish children all played in samegender dyads, but in five Swedish dyads the children preferred to play with a friend of the opposite sex. During the free play session the children were encouraged to play within the room and to use the toys available. In all situations the following toys were present: Several small cars, a mat on the floor made as the map of a town, different construction games (Lego, Kapla, building blocks), a home set (stove, table, chairs, kitchen utensils), dolls and soft animals. In the fishing game sessions, the researcher presented the fishing game and suggested that the children would try it. The game is a battery driven, round-shaped (approx. $35 \mathrm{~cm}$ in diameter) apparatus, where ten fish go round while opening and closing their mouths, and the child has to catch the fish using a fishing rod with a hook on a line that can be winded - one fishing rod for each child. A few children knew this kind of game before - there are similar but smaller variants on the market. To a majority of the children, however, it was a new toy.

Prior to recording, the researcher had spent time together with the children, participating in meals, play and other activities. The recordings were made with a very small digital video camera, positioned as far away from the children as possible. The researcher tried to keep an as "low profile" as possible, i.e. answered the childrens' questions and helped them occasionally, but otherwise did not interact with them. Without doubt, some children were more intimidated by the camera than others. On the whole, however, children of today are quite acquainted to video cameras and the majority seems not to mind very much about it.

\subsection{Coding}

Based on McDonald \& Pien (1982), all behavioral directives, i.e. utterances aimed to prompt or restrict a certain type of behavior, were identified. In addition, all utterances 
used to direct attention were included in the analysis. The coding procedures were undertaken jointly, in order to obtain a high inter rater reliability.

All behavioral directives were coded according to, addressee, focus, syntactic form, and pragmatic form according to the following:

\section{Addressee}

Peer: Regulating utterances overtly or covertly addressed towards peer. "Can you open this one for me?”, “Don’t take my fish, Anna!”

Both: Regulative utterances addressed to both children of the dyad, suggesting a joint activity. "Let's play with these cars.”, "Now, we take these two.”

\section{Focus}

Behavior: Utterances regulating behavior. "Sit down!”, "You can take that one now.”, “[You can take] that one!”

Attention: Utterances regulating attention. “Look!”, “Watch this!”, Hey, Lisa!”

\section{Syntactic form}

Imperative: Utterances regulating behavior or attention through imperatives. “Open it!”, “Take it quickly!”

Declarative: Utterances aiming to regulate behavior by declarative sentences. "We haven’t taken all fish yet."

Question: These include open questions, yes-no questions: as well as interrogative declaratives. "Can you give me the fishing rod?", "You take that one, right?"

Ellipsis: As ellipsis we have coded all one-word utterances, except imperatives, and all other incomplete utterances. Incomplete means that the utterance lacks one or more words in obligatory context, e.g. subject, verb or object etc., but where the missing element can be deduced from the context (verbal or situational) (Hansson \& Nettelbladt 1989) “The blue one, the blue one!” [Take the blue one!].

\section{Pragmatic form}

Order: A behavior directive, which either explicitly or implicitly states the action to be done. "Get her [the doll's] trousers."

Prevention: A behavior directive with an aim to prevent or hinder someone from doing something. "Stop it!”, “Don’t take my fishing rod!”

Suggestion: An utterance, which states the preferred action as a suggestion. "Let's do it all over again.”

Request: A request is a directive utterance, which is less direct than an order and less indirect than a suggestion. "Can you give her [the doll] to me?"

Statement: A directive utterance stating the action to be performed. "You can watch my baby for a while.", "We will go for a walk."

Rule comment: A sub-category of Prevention, stating that a rule is violated. "But you can not do like that.”, "One is not allowed to do like that!”, “That is cheating.” Rule-comments can also be a Statement: "The cars may only go on this side.”, "We may take the fish with our fingers."

Finally, the outcome or reactions, to the regulative were coded as:

5. Outcome - behavior

Compliance: The addressee performs the action required.

Resistance: The addressee resists the action required, either verbally by protest or non-verbally by gesture, facial expression or vocalization.

Negotiation: The addressee questions or resists the action required, and as a consequence a negotiation takes place. In order to qualify as negotiation the utterance must question the regulation (its reason, goal etc.) and end in some kind of agreement. At least three turns in follow is required.

Silence: The addressee silently ignores, or does not overtly recognize, the regulative. 
Not sure: Outcomes that are difficult to code because of recording circumstances (child turns away from camera), inaudibility etc.

\section{Outcome - attention}

Compliance: The addressee performs the action required, by either answering verbally or non-verbally, by showing attention.

Silence: The addressee silently ignores, or does not recognize, the regulative.

Not sure: Outcomes that are difficult to code because of recording circumstances (child turns away from camera), inaudibility etc.

\section{Results}

The total data adds up to 25,834 numbers of utterances (Estonian 7,315, Finnish 8,717 and Swedish 9,802). The analyzed data consists of 3,066 regulative utterances (Estonian 1,265, Finnish 1,090 and Swedish 707), which corresponds to $17 \%, 13 \%$ and $7 \%$ respectively of the total number of utterances. All groups regulate behavior more than attention (see Table 2), but the Estonian group has a slightly higher proportion of attention regulation (30\% of all regulation) than the Finnish and Swedish groups (20\% of all regulation), and conversely, Estonians have a slightly lower proportion of behavior regulation ( $70 \%$ vs. $80 \%$ of all regulation).

Table 2. Descriptive data of the speech quantity measures and regulatory utterances

\begin{tabular}{llll}
\hline & Estonian & Finnish & Swedish \\
\hline $\begin{array}{l}\text { Behavior regulation } \\
\text { (\% of all regulative utterances) }\end{array}$ & & & \\
& $904(71)$ & $880(81)$ & $575(81)$ \\
- Fishing game & 396 & 254 & 278 \\
- Play & 508 & 626 & 297 \\
$\begin{array}{l}\text { Attention regulation } \\
\text { (\% of all regulative utterances) }\end{array}$ & & & \\
& $395(29)$ & $210(19)$ & $98(19)$ \\
- Fishing game & 166 & 30 & 16 \\
- Play & 266 & 180 & 82 \\
& & & \\
\hline
\end{tabular}

\section{The amount of talk and frequency of regulation across cultures}

To compare the overall amount of talk (as measured in utterances) across samples, the mean number of utterances per minute was calculated for all samples (see Table 3), in order to eliminate the differences stemming from lengths of recordings. ANOVAs for utterances per minute revealed no significant effect of Culture (E vs $F$ vs $S$ ) at $p<.05$. In addition, the mean number of regulatory utterances per minute was calculated for both 
types of regulation across two situations for all samples. ANOVAs showed a significant effect of Culture ( $E$ vs $F$ vs S) on the total frequency of regulation $(F(2,121)=14.49$, $\mathrm{p}=.000)$, as well as separately in the fishing game situation $(\mathrm{F}(2,121)=10.62, \mathrm{p}=.000)$ and the free play situation $(\mathrm{F}(2,121)=11.51, \mathrm{p}=.000)$. Two situations taken together, the Swedish children regulated their peers significantly less frequently than their Estonian and Finnish counterparts. The same applied to the free play situation, whereas in the fishing game situation the Estonian children regulated their playmates significantly more often than children from both other samples. In the fishing game, ANOVAs revealed a significant effect of Culture ( $E$ vs $F$ vs $S$ ) both on the frequency of behavior regulation $(\mathrm{F}(2,121)=4.04, \mathrm{p}=.02)$ and on the frequency of attention regulation $(F(2,121)=30.65, p=.000)$. Also in the free play situation, ANOVAs revealed a significant effect of Culture ( $E$ vs $F$ vs $S$ ) both on the frequency of behavior regulation $(\mathrm{F}(2,121)=9.91, \mathrm{p}=.000)$ and on the frequency of attention regulation $(\mathrm{F}(2,121)=7.32$, $\mathrm{p}=.000)$.

Table 3. Frequencies of the amount of talk and two types of regulatory utterances across samples

\begin{tabular}{|c|c|c|c|}
\hline & Estonian & Finnish & Swedish \\
\hline \multicolumn{4}{|c|}{ Utterances per minute } \\
\hline Fishing & 6.94 & 6.49 & 7.19 \\
\hline Play & 5.79 & 6.79 & 6.84 \\
\hline Total & 6.18 & 6.69 & 6.88 \\
\hline \multicolumn{4}{|c|}{ Behavior regulation per minute } \\
\hline Fishing & $0.88^{\mathrm{S}}$ & 0.68 & $0.49^{\mathrm{E}}$ \\
\hline Play & $0.70^{\mathrm{S}}$ & $0.70^{\mathrm{S}}$ & $0.35^{\mathrm{E}, \mathrm{F}}$ \\
\hline \multicolumn{4}{|c|}{ Attention regulation per minute } \\
\hline Fishing & $0.35^{\mathrm{F}, \mathrm{S}}$ & $0.07^{\mathrm{E}}$ & $0.03^{\mathrm{E}}$ \\
\hline Play & $0.34^{\mathrm{F}, \mathrm{S}}$ & $0.20^{\mathrm{E}}$ & $0.11^{\mathrm{E}}$ \\
\hline \multicolumn{4}{|c|}{ All regulation per minute } \\
\hline Fishing & $1.23^{\mathrm{F}, \mathrm{S}}$ & $0.75^{\mathrm{E}}$ & $0.52^{\mathrm{E}}$ \\
\hline Play & $1.04^{\mathrm{S}}$ & $0.90^{\mathrm{S}}$ & $0.46^{\mathrm{E}, \mathrm{F}}$ \\
\hline Total & $1.08^{\mathrm{S}}$ & $0.87^{\mathrm{S}}$ & $0.50^{\mathrm{E}, \mathrm{F}}$ \\
\hline
\end{tabular}

Behavior regulation per utterance

\begin{tabular}{|c|c|c|c|}
\hline Fishing & $0.125^{\mathrm{F}, \mathrm{S}}$ & $0.100^{\mathrm{E}}$ & $0.067^{\mathrm{E}}$ \\
\hline Play & $0.136^{\mathrm{F}, \mathrm{S}}$ & $0.099^{\mathrm{E}, \mathrm{S}}$ & $0.053^{\mathrm{E}, \mathrm{F}}$ \\
\hline
\end{tabular}

Attention regulation per utterance

$\begin{array}{llll}\text { Fishing } & 0.050^{\mathrm{F}, \mathrm{S}} & 0.014^{\mathrm{E}} & 0.005^{\mathrm{E}} \\ \text { Play } & 0.069^{\mathrm{F}, \mathrm{S}} & 0.028^{\mathrm{E}} & 0.017^{\mathrm{E}}\end{array}$

All regulation per utterance

$\begin{array}{llll}\text { Fishing } & 0.174^{\mathrm{F}, \mathrm{S}} & 0.114^{\mathrm{E}, \mathrm{S}} & 0.072^{\mathrm{E}, \mathrm{F}} \\ \text { Play } & 0.205^{\mathrm{F}, \mathrm{S}} & 0.127^{\mathrm{E}} & 0.070^{\mathrm{E}} \\ \text { Total } & 0.183^{\mathrm{F}, \mathrm{S}} & 0.121^{\mathrm{E}, \mathrm{S}} & 0.074^{\mathrm{E}, \mathrm{F}}\end{array}$

Note. Superscripts show significant differences across samples at $\mathrm{p}<.05$. The samples are marked as follows: E=Estonian, F=Finnish, $S=$ Swedish 
The LSD tests showed that Estonian children regulated their peers' behavior during the fishing game significantly more often than Swedish children. During free play, both Estonian and Finnish children regulated their peers' attention significantly more frequently than Swedish children. Also, the Estonian children regulated their peers' attention significantly more often than their Finnish and Swedish counterparts across both play situations.

In order to see the relative frequency of regulation with respect to the total amount of talk, the average number of behavioral directives per utterance was also calculated across all samples (see Table 3). ANOVAs revealed significant Culture (E vs $\mathrm{F}$ vs S) effect on all regulation, two situations taken together $(\mathrm{F}(2,121)=22.81, \mathrm{p}=.000)$, as well as separately in the fishing game $(\mathrm{F}(2,121)=11.04, \mathrm{p}=.000)$ and in the free play situation $(\mathrm{F}(2,121)=13.60, \mathrm{p}=.000)$. More precisely, in the fishing game, ANOVAs revealed a significant effect of Culture ( $E$ vs $F$ vs $S$ ) on behavior regulation, $\mathrm{F}(2,121)=9.51, \mathrm{p}=.0001$, and on attention regulation, $\mathrm{F}(2,121)=32.66, \mathrm{p}=.000$. In free play, ANOVAs showed a significant Culture ( $E$ vs $F$ vs $S$ ) effect on behavior regulation, $F(2,121)=20.98, p=.000$, and on attention regulation, $F(2,121)=5.99, p=.003$. Also in relation to the total amount of talk, the Estonian children regulated their peers' attention and behavior significantly more frequently than the Swedish and Finnish children across both situations, as Figure 1 illustrates.

\section{The play situation}

Across samples, no significant statistical differences were found in the use of total regulation per utterance in two different play situations. However, t-tests for independent samples revealed a significant difference between two situations in the Swedish children's use of behavior regulation per utterance - behavior was regulated less frequently in the free play situation and more frequently during the fishing game, $t(86)=-2.83, p=.006$. In contrast, attention was regulated by the Swedish children more often in the free play situation than during the fishing game, $t(86)=2.85, p=.005$. Similarly, the Finnish children regulated their peers' attention more often in the free play situation than during the fishing game, $\mathrm{t}(74)=2.29, \mathrm{p}<.03$.

No significant differences were found also in the use of total regulation per minute in two situations across samples, but t-tests for independent samples rendered again significant differences between two situations in the Swedish children's use of attention regulation per minute - attention was regulated more often during the free play situation than the fishing game, $\mathrm{t}(86)=2.80, \mathrm{p}<.005$. The same pattern appeared in the Finnish material, the Finnish children regulated attention more often during the free play situation than the fishing game, $\mathrm{t}(74)=3.25, \mathrm{p}=.002$. 
Figure 1. The mean values of behavior and attention regulation per utterance in two play situations across samples

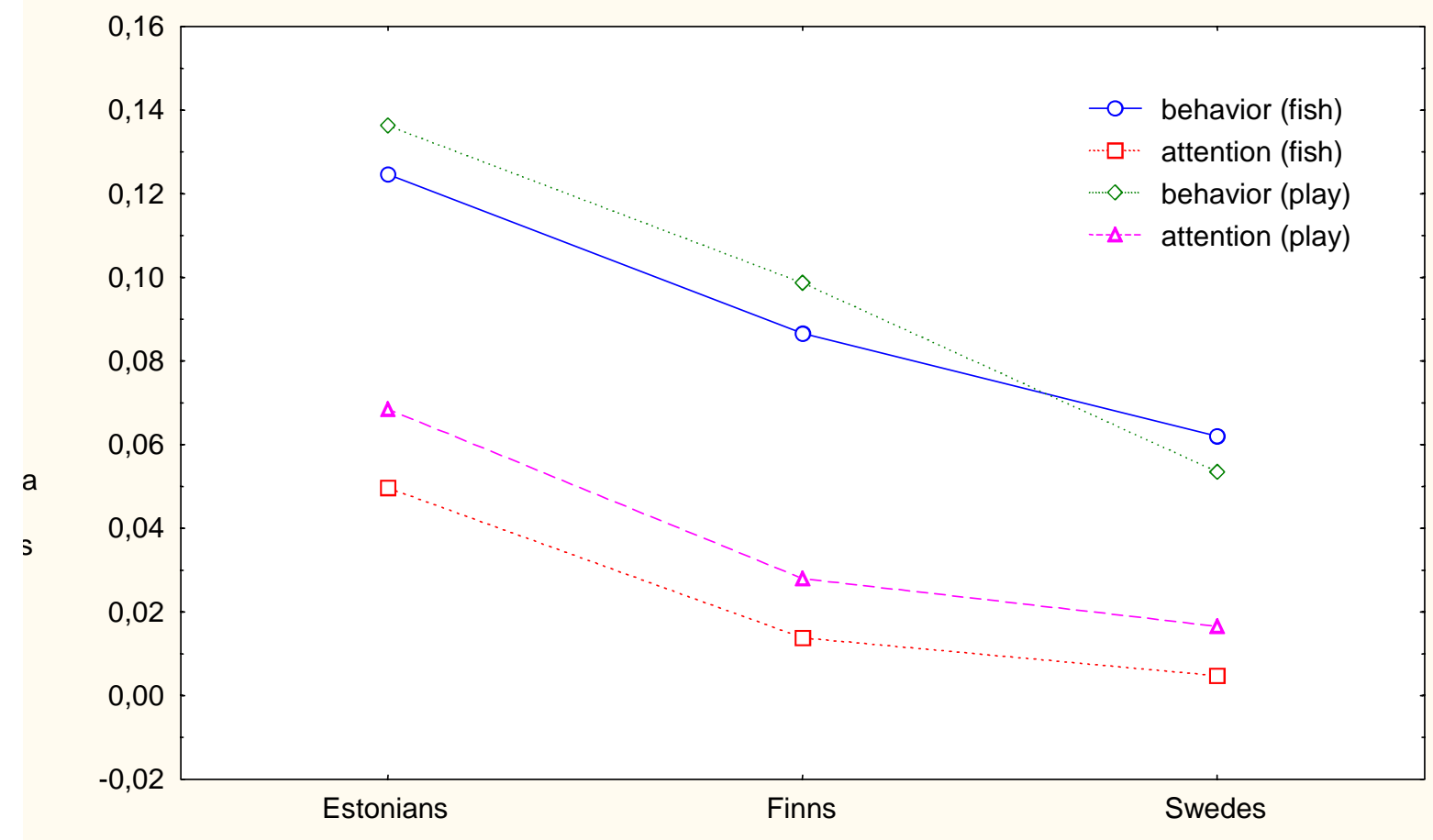

The addressee of regulation

In both play situations all groups addressed peer, i.e. the play partner, more often than both, i.e. regulation with joint reference, such as "Let's do it." (see Table 4). Finnish and Swedish children addressed peer more often in free play than during the fishing game. In contrast, both were addressed more often during the fishing game than in free play in the Finnish and Swedish sample.

Table 4. The addressees of behavior regulation in two situations per sample (in percentages)

\begin{tabular}{|c|c|c|c|c|c|c|c|}
\hline & \multicolumn{2}{|c|}{ Estonian } & \multicolumn{2}{|c|}{ Finnish } & \multicolumn{3}{|c|}{ Swedish } \\
\hline & Fishing & Free play & Fishing & Free play & Fishing & Free & play \\
\hline Peer & 78 & 75 & 79 & 86 & 70 & 87 & \\
\hline Both & 22 & 25 & 21 & 14 & 30 & 13 & \\
\hline
\end{tabular}


The syntactic form in regulation

As shown in Table 5 and illustrated by example (1) imperative was the dominant form for the Estonian and Finnish children in behavior regulation.

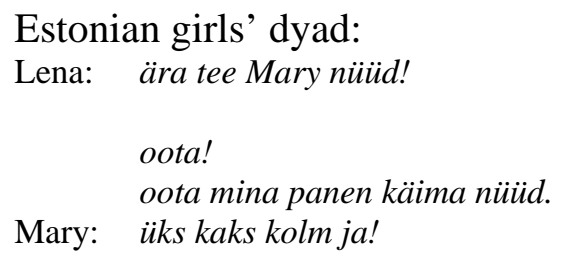

Estonian girls' dyad:

Lena: ära tee Mary nüüd!

oota!

oota mina panen käima nüüd.

Mary: üks kaks kolm ja!

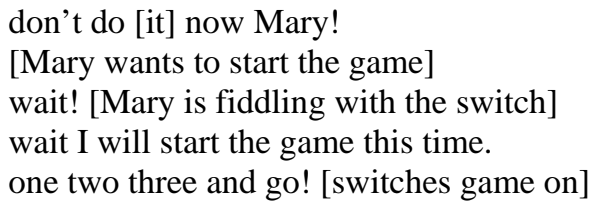

Finnish girls' dyad:
Eva: tämä laittaisi hiiren sisälle tähän. this would put the mouse into this [the oven].
Ida: laita kaikista kovimmalle. turn on the highest [temperature]. laita kuutoiselle. $\quad$ put it on [mark] six.
Eva: niin. yes.
Ida: älä vielä syö sitä. $\quad$ don't eat it yet.

Table 5. The syntactic form of behavior and attention regulation in two situations per sample (percentages of all behavior regulation utterances)

\begin{tabular}{|c|c|c|c|c|c|c|}
\hline & \multicolumn{2}{|c|}{ Estonian } & \multicolumn{2}{|c|}{ Finnish } & \multicolumn{2}{|c|}{ Swedish } \\
\hline & Fishing & Free play & Fishing & Free play & Fishing & Free play \\
\hline \multicolumn{7}{|c|}{ Behavior regulation } \\
\hline Imperatives & 67 & 78 & 74 & 74 & 24 & 31 \\
\hline Declaratives & 21 & 17 & 9 & 10 & 58 & 47 \\
\hline Questions & 8 & 3 & 6 & 6 & 8 & 9 \\
\hline Ellipses & 4 & 2 & 11 & 10 & 10 & 13 \\
\hline \multicolumn{7}{|c|}{ Attention requlation } \\
\hline Imperatives & 82 & 85 & 63 & 81 & 38 & 40 \\
\hline Ellipses & 18 & 15 & 37 & 19 & 62 & 60 \\
\hline
\end{tabular}

The Swedish children preferred to regulate behavior predominantly by declaratives: Nu kan du ta honom! "Now you can take him!”, Du får inte ta mina fiskar. "You must not take my fish" Om du sätter henne i den röda vagnen så kan jag ta kort. "If you put her [a doll] in the red pram I can make a photo" and imperatives: Sluta att bråka! ”Stop fussing!”, Titta i spegeln! ”Look in the mirror!”.

In attention regulation Estonian and Finnish children used mainly imperatives (see Table 5), as example (2) illustrates.

Estonian girls' dyad:

Petra: vaata seda rohelis!

Siri: look at the green [fish]!

[Siri is busy catching another fish] 


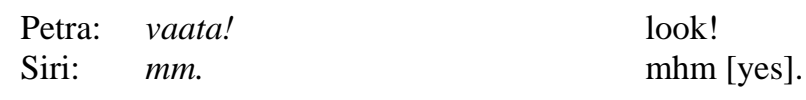

Finnish boys' dyad:

\begin{tabular}{|c|c|c|}
\hline sak: & $\begin{array}{l}\text { tämmönenkin nappasi minulla. } \\
\text { ja kala. }\end{array}$ & $\begin{array}{l}\text { I caught a fish like this. } \\
\text { and a fish [shows the fish]. }\end{array}$ \\
\hline Jussi: & $\begin{array}{l}\text { katso. } \\
\text { mina en ole vielä saanut. } \\
\text { aika vaikea peli. }\end{array}$ & $\begin{array}{l}\text { look. } \\
\text { I haven't got any yet. } \\
\text { quite a difficult game. }\end{array}$ \\
\hline
\end{tabular}

Swedish children used various types of ellipses indicating the peer's name, the peer's role in the game, like Mamma!, "Mummy!" or Storebror!, "Big brother!”, or some other summons, like Hallå!, “Hello!”, Du!, “You!” or Vet du? "You know?”.

The pragmatic form of behavior regulation

Order was the most frequent pragmatic form used by Estonian and Finnish children in behavior regulation. Closely connected to order is prevention, where the goal is to stop an activity. Prevention was used in all three groups, but more by Estonian and Finnish children during the fishing game, and more by Swedish children in free play (see Table $6)$.

Table 6. The pragmatic form of behavior regulation in two situations per sample (percentages of all behavior regulation utterances)

\begin{tabular}{lcccrrr}
\hline & \multicolumn{2}{c}{ Estonian } & Finnish & \multicolumn{2}{c}{ Swedish } \\
& Fishing & Free play & Fishing & Free play & Fishing & Free play \\
& & & & & & \\
Order & 43 & 54 & 35 & 51 & 14 & 19 \\
Prevention & 30 & 11 & 36 & 23 & 21 & 23 \\
Suggestion & 17 & 27 & 22 & 16 & 18 & 19 \\
Request & 1 & 4 & 1 & 5 & 1 & 4 \\
Statement & 3 & 4 & 2 & 3 & 38 & 30 \\
$\quad-$ rule statement & 6 & 0 & 4 & 2 & 10 & 5 \\
\hline
\end{tabular}

An example of prevention in a Swedish mixed dyad is brought in example (3), where Maria twice prevents Andreas from taking her babies:

(3) Swedish mixed dyad:

$\begin{array}{lll}\text { Andreas: } & \begin{array}{l}\text { du hade tre bebisar. } \\ \text { jag tog två. }\end{array} & \text { you had three babies. } \\ & \text { dom här två tog jag. } & \text { I took two. } \\ \text { Maria: } & \text { men inte två! } & \text { these two I took. } \\ \text { Andreas: } & \text { vi+/ okej jag tar den här. } & \text { but not two! } \\ \text { Maria: } & \text { nej inte den. } & \text { we+/ okay I take this one. }\end{array}$

All three groups also frequently used suggestion, as example (4) illustrates. 


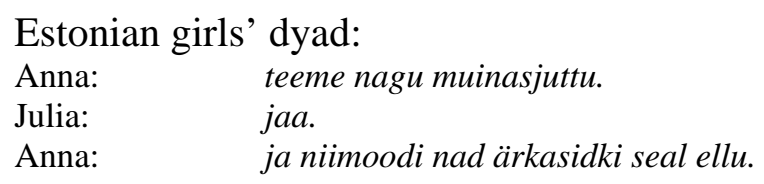

let's make it into a fairy tale.

yes.

and so there they became alive again.

okay let's play a new game.

we have caught all.

let's play a new game.

I got more.

$+<$ let's play this again.

Statements were used to a great extent by Swedish children, both during fishing game: Nu ska vi lägga tillbaks alla fiskar och köra en gång till. "Now we will put all fish back and do it once again.”, Vi sätter fast den på var sin och så fångar vi dom. "We put it [attach it] on one each and then we catch them", and in free play: Du ska jaga mig alltså. "You will chase me that is." Det är du som fixar lillorna. "It is you who fix the little ones.” Du får vakta min unge. "You will guard my baby."

Rule comments were treated separately, and could be both preventive - typically during the fishing game: Man får inte göra så där! "You are not allowed to do like that!”, Det är fusk att göra så! "It is cheating to do like that!”, but can also occur in free play: Man får bara åka på gatan. "You are only allowed to drive in the street" or Rondellen då måste man köra runt fem gånger. "The roundabout then you must drive round it five times."

\section{The outcome of behavior and attention regulation}

In behavior regulation, compliance to the behavioral directive was the most common outcome category across all three samples and the Swedish children complied slightly more often than the Estonian and Finnish children (see Table 7). Rejection and negotiation were the least common categories in behavior regulation in all groups. The three groups were fairly similar in rejection, whereas the Swedish children more often negotiated than the Estonian and Finnish children. Also, the Swedish children had fewer cases of silence than the Estonian and Finnish children.

There were, however, differences between the play situations: During the fishing game silence was a considerably more common outcome following regulation than 
during free play for the Estonian and the Swedish group. On the other hand, there were no differences concerning silence in the two play situations for the Finnish children.

Table 7. The outcome of behavior and attention regulation in two situations per sample (percentages ofrespectively - all behavior and attention regulation utterances)

\begin{tabular}{|c|c|c|c|c|c|c|}
\hline & \multicolumn{2}{|c|}{ Estonian } & \multicolumn{2}{|c|}{ Finnish } & \multicolumn{2}{|c|}{ Swedish } \\
\hline & Fishing & Free play & Fishing & Free play & Fishing & Free play \\
\hline \multicolumn{7}{|c|}{ Behavior regulation } \\
\hline Compliance & 39 & 59 & 62 & 55 & 58 & 67 \\
\hline Resistance & 10 & 11 & 10 & 12 & 8 & 13 \\
\hline Negotiation & 4 & 6 & 2 & 5 & 10 & 11 \\
\hline Silence & 33 & 16 & 22 & 26 & 20 & 5 \\
\hline Not sure & 14 & 8 & 4 & 2 & 4 & 4 \\
\hline \multicolumn{7}{|c|}{ Attention regulation } \\
\hline Compliance & 78 & 86 & 80 & 65 & 67 & 87 \\
\hline Silence & 17 & 13 & 20 & 34 & 33 & 13 \\
\hline Not sure & 5 & 1 & 0 & 1 & 0 & 0 \\
\hline
\end{tabular}

Also in attention regulation compliance was the most frequent outcome. The Swedish children most often acknowledged an attention regulative overtly - either verbally or non-verbally - and particularly during free play. Most often, Ja., "Yes." or Mm positively acknowledged a vocative. Example (5) illustrates attention regulation and its outcome in three Swedish dyads.

\begin{tabular}{|c|c|c|}
\hline \multicolumn{3}{|c|}{ Swedish boys’ dyad: } \\
\hline Johan: & kolla här! & check this! \\
\hline Anders: & jag vet. & I know. \\
\hline \multicolumn{3}{|c|}{ Swedish girls' dyads: } \\
\hline $\begin{array}{l}\text { Jenny: } \\
\text { Marta: }\end{array}$ & $\begin{array}{l}\text { Marta titta så många vi har! } \\
\text { en hel hög! }\end{array}$ & $\begin{array}{l}\text { Marta look how many we've got! } \\
\text { a whole pile! }\end{array}$ \\
\hline Mimmi: & kolla här! & check this! \\
\hline Maja: & en indian. & an Indian. \\
\hline
\end{tabular}

In attention regulation the results were even more striking with high share of silence in the Finnish group and also in the Swedish group during fishing.

\section{Discussion}

The study indicated both similarities and differences in the regulatory language used in play in our study of kindergarten peer dyads in Estonia, Finland and Sweden. 


\section{Amount of speech}

No significant differences were found regarding amount of speech as measured in number of utterances per minute. It is interesting to notice, however, that whereas the Swedish children's amount of speech does not differ from several previous studies, it does for the Estonian and Finnish children, who speak more during peer play than in family dinner conversation. The result therefore contradicts earlier research about silent Finns or Finno-Ugrics as opposed to more talkative Swedes (Lehtonen 1993; Sajavaara \& Lehtonen 1997), as well as our previous results from family interaction (e.g. De Geer et al. 2002; Tulviste et al. 2003b).

We would, however, like to suggest that these results support the claims (e.g. De Geer 2002; Tulviste et al. 2003a) about the symmetric interaction style of Swedish families, and the more asymmetric style of the Estonian and Finnish families. Without the influence of parents, or maybe adults, the Estonian and Finnish children produce more speech, whereas the Swedish children talk as much in family and peer interaction. Furthermore, we found the same differences in amount of talk also for mothers and fathers, i.e. Swedish parents spoke significantly more than Estonian and Finnish parents (De Geer et al. 2002). This would imply that it is the presence of parents that make Estonian and Finnish children talk less. In combination with the comparatively authoritative and asymmetrical family system of Estonia and Finland this renders taciturn children.

A comparison of amount of speech in the present and previous studies is provided in Table 8.

Table 8. Amount of speech, mean numbers of utterances per minute

\begin{tabular}{llll}
\hline & Estonian & Finnish & Swedish \\
\hline Tulviste et al. (2003b) & 4.17 & 4.43 & 6.29 \\
The present study & 6.18 & 6.69 & 6.88 \\
\hline
\end{tabular}

\section{The amount of regulation}

Whilst the children in all three groups were as talkative, Estonian children were found to use regulation more than Finnish children, who in turn used regulation more than Swedish children. All these differences were statistically significant. The study is therefore in line with the earlier findings of Junefelt and Tulviste (1997) who found that mothers in Estonia were more controlling than Swedish mothers, in that they used more behavioral directives towards their two-year-olds; the results of Tulviste (2000), who found Estonian mothers of children to be both regulating behavior and commenting on behavior more than American mothers; as well as the results of De Geer \& Tulviste (2002), which showed that Estonian families are significantly more regulating than Swedish families.

It is also interesting to compare figures of a number of similar studies: The toddlers studied by Tulviste and Junefelt $(1997,1998)$ were much more regulated by 
their mothers than the preadolescent children (9-13 years) of De Geer \& Tulviste (2002). Furthermore, mothers of teenagers regulated their children the least (Tulviste 2000).

Table 9 gives a developmental picture of the use of regulation of and by children in different settings. Although from different recording situations (mealtime, puzzle solving, free play, game play) and although the data are not complete, the results indicate that with increasing age of the child, mothers regulate behavior less. Also, peers regulate each other's behavior more than they regulate their parents' behavior.

Table 9. Regulation of behavior and attention, regulative utterances per minute in similar studies

\begin{tabular}{|c|c|c|c|}
\hline & Estonian & Finnish & Swedish \\
\hline \multicolumn{4}{|l|}{ Behavior requlation } \\
\hline $\begin{array}{l}\text { Tulviste \& Junefelt (1998), mothers to 2-year-olds } \\
\qquad 4.60 / 1.90^{*}\end{array}$ & $7.70 / 2.30 *$ & - & \\
\hline Tulviste \& Raudsepp (1997), mothers to 4-year-olds & $1.72 / 2.15^{*}$ & - & - \\
\hline De Geer \& Tulviste (2002), mothers to 9-13-year-olds & 0.54 & - & 0.44 \\
\hline Tulviste (2000), mothers to teenagers & 0.52 & - & - \\
\hline De Geer \& Tulviste (2002), children to mothers & 0.03 & - & 0.19 \\
\hline Tulviste (2000), teenagers to mothers & 0.19 & - & - \\
\hline De Geer et al. (2000) mothers to 9-13 year-olds & & 0.25 & \\
\hline De Geer et al. (2000) children to mothers & & 0.03 & \\
\hline The present study, kindergarten peers & $0.88 / 0.70^{* *}$ & $0.68 / 0.70 * *$ & $0.49 / 0.35 *$ \\
\hline \multicolumn{4}{|l|}{ Attention regulation } \\
\hline Tulviste \& Junefelt (1998), mothers to 2-year-olds & $3.60 / 0.30 *$ & - & $1.10 / 0.30 *$ \\
\hline Tulviste \& Raudsepp (1997), mothers to 4-year-olds & $1.40 / 0.20^{*}$ & - & - \\
\hline De Geer et al. (2000), mothers to 9-13-year-olds & 0.01 & 0.01 & 0.04 \\
\hline De Geer et al. (2000), children to mothers & 0.00 & 0.04 & 0.05 \\
\hline The present study, kindergarten peers & $0.34 / 0.35^{* *}$ & $0.07 / 0.20 * *$ & $0.03 / 0.11^{* *}$ \\
\hline $\begin{array}{l}*=\text { Different values for puzzle solving/mealti } \\
* * \text { = Different values for game play/free play }\end{array}$ & & & \\
\hline
\end{tabular}

Our results further showed that attention regulation was most common in the Estonian group, least in the Swedish, and the Finnish group was found in between. Like behavior regulation, attention regulation from the mothers' side decreases considerably when children grow older. The most interesting finding is probably that Swedish children use quite little attention regulation and they also use the same low amount of attention regulation both toward mothers and to peers. Estonian children, and to some extent also Finnish children, use considerably less attention regulation toward mothers than toward peers. This, again, is a reflection of the more asymmetric parent-child relations of Estonia and Finland. 


\section{The addressee of regulation}

Not very surprisingly, peer was the most common addressee in behavior regulation in all three groups, with approx. 75\% of the utterances. In the Estonian group, there was no difference between the two situations fishing or free play. However, for Finnish and particularly Swedish children there were differences. Both groups had lower shares of the category both during free play - only $14 \%$ and $13 \%$ respectively.

Apart from the fact that the fishing game is a competitive game, it also involves cooperation. There are many actions to carry out together - starting and stopping the game, putting the fish back before making another round etc. During the fishing game the Swedish children used the highest proportion of joint regulation, i.e. category both.

However, the Finnish and Swedish children had higher share of the category peer in the free play situation - $86 \%$ and $87 \%$ as compared to the Estonians' $75 \%$. This may indicate a slightly higher degree of independence among the Finnish and Swedish children during free play. They more frequently regulate each other as individuals, as in example (6), rather than launch joint ventures.

(6) Swedish girls’ dyad (two girls building a house with Kapla blocks):

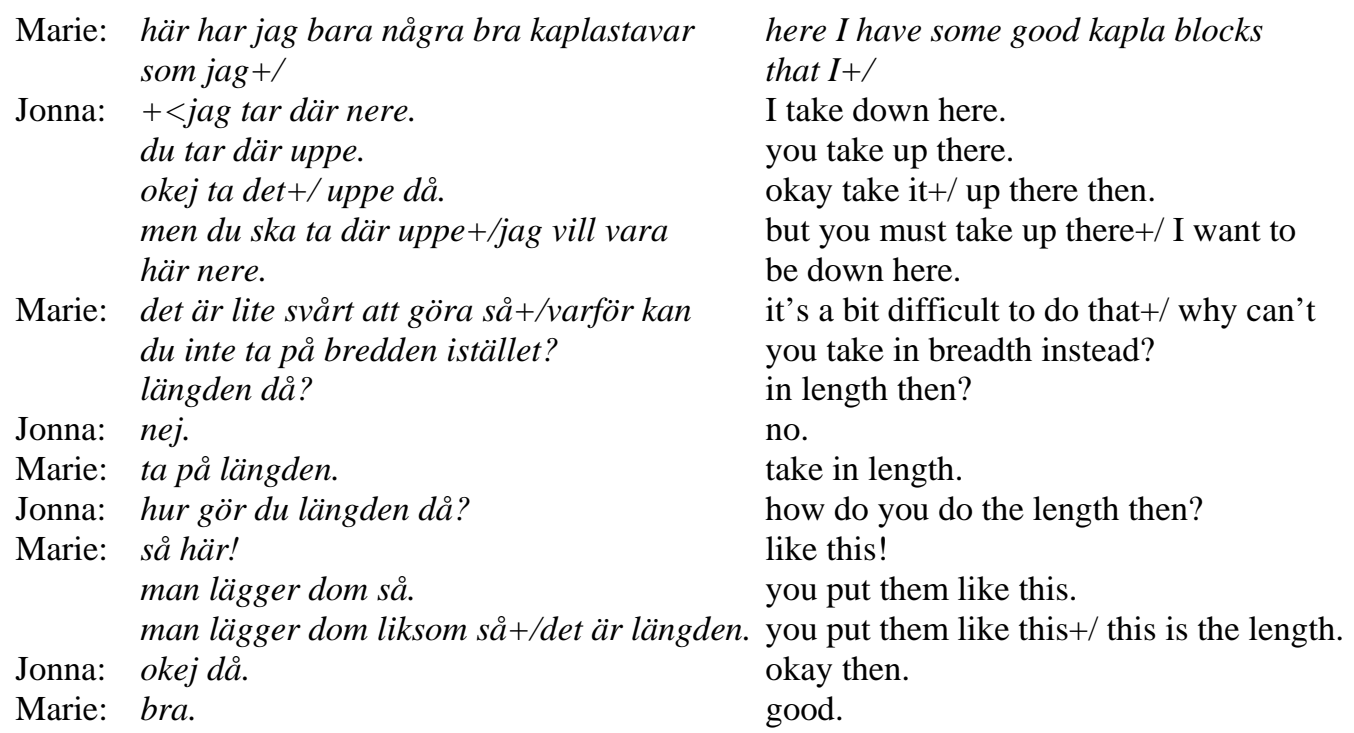

\section{The syntactic and pragmatic form in regulation}

Different syntactic forms are used in regulation of behavior in the three groups. The Estonian and the Finnish children use imperatives most frequently, whereas the Swedish children use more declaratives and imperatives in behavior regulation. These findings confirm the results of Junefelt \& Tulviste (1998), where showed that Estonian mothers use more imperatives than Swedish mothers. It was however noticed by De Geer \& Tulviste (2002) that in Swedish families, both adults and children regulated behavior with means of declaratives and questions. It is interesting to notice that questions are not used much by the Swedish children of this study. Questioning is a very indirect means 
of regulation and indeed, whenever questions occur in our Swedish data, the action regulated involves some kind of effort or sacrifice from the addressee's point of view, e.g.: Kan du sätta på den här på honom? "Can you put this one on him [a doll]?”, Kan du spara resten åt mej? "Can you save the rest [of the fish] for me?" These questions are pragmatically sophisticated, in that they are open for the possibility of a rejection. It would be reasonable to assume that this is a skill that children acquire late and this would explain the higher share of questions in De Geer \& Tulviste (2002), where the children are older. Also, the fact that peer interaction may sometimes be more symmetrical than adult-child interaction, can explain why the more indirect, and thus polite, way of regulation behavior with questions is less frequent in peer dyads.

Also in attention regulation the imperative is dominating in the Estonian and Finnish data, whereas in the Swedish dyads ellipses are more common.

Like imperatives were very common syntactic forms of regulation in the Estonian and Finnish groups, orders dominated the pragmatic forms. Orders can of course also be expressed by i.e. statements, but imperatives are more frequent. Imperatives are also frequent in preventions, which are common in the Estonian and Finnish groups, particularly during the fishing game.

\section{The outcome of behavior regulation}

Compliance was the most common outcome category to behavioral directives in all three groups, which confirms the findings of De Geer \& Tulviste (2002). Also, the percentage shares of compliance as well as resistance were similar to the shares of the previous study. The category negotiation was not used in De Geer \& Tulviste (2002). It proved to be slightly more common in the Swedish group than in the Estonian and the Finnish ones and has also been found to be more frequent in Swedish groups in several previous studies (De Geer et al. 2000; De Geer \& Tulviste 2004). If the categories resistance and negotiation are collapsed the Swedish group stands out even clearer particularly during free play where $24 \%$ of the Swedish children's outcome is resistance and negotiation. It has also been pointed out by Dahlberg (1992) that Swedish child socialization is very much in favor of promoting children's participation in decisionmaking and negotiation, a behavior likely to be manifested through negotiation.

The differences between the play situations concerning silence, which was found to be more common during the fishing game than during free play for the Estonian and Swedish groups seem likely to be explained by the high amount of concentration needed to succeed in catching the fish. On the other hand, there were no differences concerning silence in the two play situations for the Finnish children. Instead, they had a similar share of silence during free play as the Estonian group. The Swedish children had an outstandingly low share of silence in their outcome of regulation.

It was concluded in De Geer \& Tulviste (2002) that silence following behavior regulation may suggest both protest as well as agreement. It may, however, also indicate that Swedes are more dependent on, or inclined to make, verbal acknowledgement in conversation than Estonians and Finns. The latter are more tolerant towards silence (cf. Kivik 1998), or rather - they use silence as a signal saying: "I hear you, please go on". 


\section{The outcome of attention regulation}

Also in attention regulation, compliance dominates in all groups and in both situations. The Estonian children regulate attention the most and they are also complying most with attention regulation. Finnish children, on the other hand, are more silent following attention regulation during free play and the Swedish children are more silent during the fishing game. This behavior is difficult to interpret and explain.

It is interesting to note that the Estonian and Finnish children use attention regulation the most. It is also the Estonian and Finnish children who are more silent in reply to behavior regulation. So, could attention regulation be a way of signaling that you are not pleased with your partner's silence? More and deeper research is of course needed to answer this question.

\section{Conclusions}

We can conclude that five of our seven hypotheses were confirmed.

Contrary to our expectations, we found no significant differences as regards amount of speech measured in number of utterances per minute and child. Whilst the Swedish children's amount of speech corresponded to previous studies, the Estonian and Finnish children spoke more during peer play than in family dinner conversation. Furthermore, we expected the Swedish children to regulate jointly, by we-constructions, in a higher degree than the Estonian and Finnish children. This hypothesis was also falsified.

On the other hand, the Estonian children proved to regulate more than the Finnish children, who in turn regulated more than the Swedish children. This concerned both behavior and attention. Attention regulation was also more common in this study than in the family study (De Geer \& Tulviste 2002).

In addition, the Estonian and Finnish children used more direct syntactic forms in regulation than the Swedish children. This pattern was repeated in their use of pragmatic form. Finally, both Estonian and Finnish children more often remained silent when their behavior was regulated.

Although based on different data corpuses, we dare to conclude that the kindergarten children of the present study follow the common cultural interaction patterns of their cultural fellowmen - both adults and adolescents - when it comes to controlling behavior, as well as syntactic means of control and in outcomes following regulation. The interesting point is, however, that the Estonian and Finnish children only do it with their peers, whereas the Swedish children behave the same way both with parents and with peers. Thus, these results further confirm the claims made about the symmetric interaction style of Swedish families (Welles-Nyström 1996) and kindergarten settings (Aronson \& Evaldsson 1993), as well as the more asymmetric style of the Estonian and Finnish families (e.g. De Geer 2002; Tulviste et al. 2003a).

They further support the claim about the general high degree of independence and self-assertiveness that is stressed in Swedish child rearing, as opposed to other types of behavior (Ekstrand \& Ekstrand 1985; Daun 1991). We can, however, also argue that the Estonian and Finnish children do assert themselves in peer interaction by reproducing the controlling behavior of their parents. Furthermore, together with peers the Estonian and Finnish children are being assertive through their amount of talk, 
which is equal to that of the Swedish children. Further studies on peer interaction in these cultures are needed in order to identify the differences between adult-child and child-child interaction.

\section{References:}

Andersen, Elaine Slosberg (1990) Speaking with style: The sociolinguistic skills of children. London: Routledge.

Aronsson, Karin, \& Ann-Carita Evaldsson (1993) Pedagogic discourse and interaction orders: Sharing time and control. In N. Coupland \& J.F. Nussbaum (eds.), Discourse and lifespan identity. London: Sage Publications, pp 103-131.

Becker, Judith (1988) The success of parents' indirect techniques for teaching their preschoolers pragmatic skills. First Language 8: 173-181.

Becker, Judith (1990) Processes in the acquisition of pragmatic competence. In Gina Conti-Ramsden \& Catherine Snow (eds.), Children's Language 7. Hillsdale: Lawrence Erlbaum Ass, p. 7-24.

Blum-Kulka, Shoshana (1997) Dinner talk. Cultural patterns of sociability and socialization in family discourse. Mahwah: Lawrence Erlbaum Ass.

Bornstein, M.H., J. Tal, \& C.S. Tamis-LeMonda (1991) Parenting in cross-cultural perspective: The United States, France, and Japan. In M.H. Bornstein (ed.), Cultural approaches in parenting. Hilldale, NJ: Lawrence Erlbaum Ass., pp. 69-90.

Clancy, P. (1986) The acquisition of communicative style in Japan. In B. Schiefflelin \& E. Ochs (eds.), Language socialization across cultures. Cambridge: Cambridge University Press, p. 213-250.

Dahlberg, Gunilla (1992) The parent-child relationship and socialization in the context of modern childhood: The case of Sweden In J.L. Roopnarine \& D.B. Carter (eds.), Parent-Child socialization in diverse cultures. Norwood, NJ: Ablex Publishing Corp., pp. 121-137.

Daun, Åke (1991) Individualism and collectivity among Swedes. Ethnos 56.3-4: 165-172.

De Geer, Boel, \& Tiia Tulviste (2002) Behaviour regulation in the family context in Estonia and Sweden. Pragmatics 12.3: 329-346.

De Geer, Boel, \& Tiia Tulviste (2004) Cooperation and competition in play: A comparative study of Estonian, Finnish and Swedish peer interaction. Manuscript.

De Geer, Boel, Tiia Tulviste, Luule Mizera, \& Marja-Terttu Tryggvason (2000) Regulatory speech in the family context in Estonia, Finland and Sweden. Manuscript.

De Geer, Boel, Tiia Tulviste, Luule Mizera, \& Marja-Terttu Tryggvason (2002) Socialization in communication: Pragmatic socialization during dinnertime in Estonian, Finnish and Swedish families. Journal of Pragmatics 34: 1757-1786.

Ekstrand, Lars, \& Gudrun Ekstrand (1985) Patterns of socialization in different cultures: The cases of Sweden and India. In R. Diaz-Guerrero (ed.), Cross-cultural and national studies in social psychology. Selected papers from the 23th International Congress of Psychology. Amsterdam: North-Nolland. Vol 2: 225-244.

Goodwin, Marjorie Harness (1990) He-Said-She-Said. Talk as social organization among black children. Bloomington and Indianapolis: Indiana University Press. 
Halle, Tamara, \& Marilyn Shatz (1994) Mothers' social regulatory language to young children in family settings. First Language 14: 83-104.

Hansson, Kristina, \& Ulrika Nettelbladt (1989) The verbal interaction of language disordered preschool children. Grammatical analysis: Method and results from a pilot study. Lund University: Working Papers in Logopedics and Phoniatries 5: 8-36.

Heath, Shirley Brice (1983) Ways with words: Language, life and work in communities and classrooms. Cambridge: Cambridge University Press.

Hoff-Ginsberg, Erica (1991) Mother-child conversation in different social classes and communicative settings. Child Development 62: 782-796.

Junefelt, Karin, \& Tiia Tulviste (1997) Regulation and praise in American, Estonian and Swedish motherchild interaction. Mind, Culture and Activity 4.1: 24-33.

Junefelt, Karin, \& Tiia Tulviste (1998) American, Estonian and Swedish mothers' regulation of their children's discourse construction. In M. Lyra \& J. Valsiner (eds.), Construction of psychological processes in interpersonal communication, pp. 137-154.

Kivik, Piibi-Kai (1998) What silence says: Communicative style and identity. Trames 2.52/47: 66-90.

Kuczynski, Leon, Grazyna Kochanska, Marian Radke-Yarrow, \& Girnius-Brown (1987) A developmental interpretation of young children's noncompliance. Developmental Psychology 23.6: 799806.

Kulick, Don (1990) Having head and showing knowledge. Department of Anthropology: Stockholm University.

Lehtonen, Jaakko (1993) Puhekasvatus ja sosiaaliset taidot. In J. Lehtonen (ed.), Kultuttuurien kohtaaminen: Näkökulmia kulttuurienväliseen kanssakäymiseen. Jyväskylö: University of Jyväskylä, Department of Communication. pp. 43-59.

McDonald, Lynda, \& Diana Pien (1982) Mother conversational behaviour as a function of interactional intent. Journal of Child Language 9: 337-358.

Ochs, Elinor (1988) Culture and language development: Language acquisition and language socialization in a Samoan village. Cambridge: Cambridge University Press.

Ochs, Elinor (1996) Linguistic resources for socializing humanity. In John Gumperz \& Stephen Levinson (eds.), Rethinking linguistic relativity. Cambridge: Cambridge University Press, pp. 407-437.

Pan, B.A., A. Imbens-Bailey, J. Winner, \& C. Snow (1996) Communicative intents expressed by parents in interaction with young children. Merrill-Palmer Quarterly 42: 248-267.

Pontecorvo, Clotilde (1998) Discourse and socialization in families. Paper presented at the fourth Congress of the International Society for Cultural Research and Activity Theory. Århus, Denmark.

Sajavaara, Kari, \& Jaakko Lehtonen (1997) The silent Finn revisited. In A. Jaworsky (ed.), Silence: Interdisciplinary perspectives. Berlin: Mouton de Gruyter, pp. 263-283.

Schaffer, H.R. (1999) Understanding socialization: From unidirectional to bidirectional conceptions. In M. Bennett (ed.), Developmental Psychology: Achievements and prospects. Philadelphia, PA: Psychology Press, pp. 272-288.

Shieffelin, Bambi, \& Elinor Ochs (1986) Language socialization across cultures. Cambridge: Cambridge University Press. 
Tannen, Deborah (1981) Indirectness in discourse: Ethnicity as conversational style. Discourse Processes 4: 221-238.

Tryggvason, Marja-Terttu, \& Boel De Geer (2002) Eliciting talk as language socialization in Finnish, SwedishFinnish and Swedish families: A look at syntactic structures. Multilingua 21: 345-369.

Tulviste, Tiia, \& Margit Raudsepp (1997) The conversational style of Estonian mothers. First Language 17: 151-163.

Tulviste, Tiia (2000) Socialization at meals. A comparison of American and Estonian mother-adolescent Interaction. Journal of Cross-Cultural Psychology 13.5: 537-556.

Tulviste, Tiia; Luule Mizera, Boel De Geer, \& Marja-Terttu Tryggvason (2003a) A comparison of Estonian, Swedish, and Finnish mothers' controlling attitudes and behaviour. International Journal of Psychology 38.1: 46-53.

Tulviste, Tiia, Luule Mizera, Boel De Geer, \& Marja-Terttu Tryggvason (2003b) A silent Finn, a silent Finno-Ugric, or a silent Nordic? A comparative study of Estonian, Finnish, and Swedish motheradolescent interactions. Applied Psycholinguistics 24: 249-265.

Tulviste, Tiia, Luule Mizera, \& Boel De Geer (2004) Expressing communicative intents in Estonian, Finnish, and Swedish mother-adolescent interactions. Journal of Child Language 31.3: 1-19.

Valsiner, Jaan (1987) Culture and the development of children's actions. A cultural-historical theory of developmental psychology. New York: Wiley.

Welles-Nyström, Barbara (1996) Scenes from a marriage: Equality ideology in Swedish family policy, maternal ethnotheories, and practice. In Sarah Harkness \& Charles M. Super (eds.), Parents’ cultural belief systems: Their origins, expressions, and consequences. New York: Guilford, pp. 192-214. 